\title{
Use a Compass to Decide
}

Aircraft construction with plastics, convenient smartphones whose processing power would have been enough to put a man on the moon in the 1960s: much of what seemed hard to image a few decades ago is nothing to write home about these days. We now teach materials and machines how to communicate, and reverently await the arrival of quantum computing, which will concentrate the entire computing capacity currently available into a machine of compact proportions.

Our economy, which is geared for growth, demands technical progress - and we are happy to supply it. With every research project and with every newly developed technology. And with it, we supply the foundations for the world in which we will live tomorrow.

In December, the Stifterverband (Donors' Association) published figures on research and development spending by German companies. Business invested 62.9 billion euros in technological progress in 2016 - 3.1 percent up on the previ- ous year. This is welcome news, as investment also safeguards our jobs in an ever-changing world. Incidentally, the automotive industry is a very keen investor, having spent 21.9 billion euros internally on research and development.

Investment is primarily decided according to business criteria; investors wish to make a return at some later date. However, the overall implications of these decisions goes far beyond business: every euro invested in research is a decision for a specific future and against many others that are possible. We actively choose the future in which we wish to live.

The latest forecasts again predict a stable economy and hence brisk investment in research and development in Germany and around the world for this year. I am hoping for new technology that is affordable, that benefits people and that is compatible with the environment. I wish all decision makers a dependable internal compass for the many forthcoming important strategic decisions that they will take. 